\section{Guiding policy to reduce the burden of COPD: the role of epidemiological research}

\author{
Guy B Marks ${ }^{1,2}$
}

In Thorax, Bhatt and colleagues' interesting cross-sectional analysis of data from the COPDGene study cohort demonstrates, somewhat unsurprisingly, that the compound (multiplicative) measure of cumulative exposure to tobacco smoking, 'pack-years', is a suboptimal index of exposure with respect to effects on indices of airflow obstruction, spirometric lung volume and emphysema. ${ }^{1}$ This is unsurprising because there is no biological basis for assuming that the effects should be manifest by a simple multiplicative relationship between duration of smoking and estimated average number of cigarettes smoked per day. Compound measures are convenient, but usually not robust, measures for epidemiological investigation. This study confirms that it is almost always more appropriate (and powerful) to analyse the individual components of the exposure separately and to model the interaction between them.

Perhaps more surprising is the near absence of any effect of the estimated average number of cigarettes smoked per day on the spirometric and radiological endpoints. The authors offer a number of plausible potential explanations for this negative finding. These include methodological limitations: non-differential measurement error in the estimation of number of cigarettes smoked per day and the limited variation in number of cigarettes smoked per day in the study population. All participants in the COPDGene cohort study were current or ex-smokers with at least 10 pack-years of smoking history. It is also likely that the method of recruitment may have favoured people with symptoms of lung disease, though those with diagnosed lung disease other than COPD and asthma were excluded. This could have further limited the range of variability in the data. There are also

\footnotetext{
${ }^{1}$ Respiratory and Environmental Epidemiology, Woolcock Institute of Medical Research, Sydney, Australia

${ }^{2}$ South Western Sydney Clinical School, University of New South Wales, Sydney, Australia
}

Correspondence to Dr Guy B Marks, Respiratory and Environmental Epidemiology, Woolcock Institute of Medical Research, Sydney, NSW 2050, Australia; g.marks@unsw.edu.au potential biological explanations for the lack of association with number of cigarettes smoked, including the propensity of individuals to inhale more deeply when they smoke fewer cigarettes (or when they smoke cigarettes with a lower nicotine content). ${ }^{2}$ It is for this reason that it is inappropriate to use the shorthand term 'smoking intensity' to describe the number of cigarettes smoked per day.

The major question raised by this article is: where should we go from here? Good quality evidence of a likely causal association between smoking and death due to COPD has been available for at least 40 years. ${ }^{3}$ There is little doubt about the need for policy and practice to prevent smoking uptake and assist in cessation. It seems unlikely that this will be changed by further research on the dose-response relation for smoking and COPD. WHO's Framework Convention for Tobacco Control, which has been ratified by 180 parties representing 90\% of the world's population, ${ }^{4}$ charts a pathway for global action. It is summarised as MPOWER and includes a range of strategies suitable for implementation by clinicians and government agencies, including health promotion and advocacy (including opportunistic brief advice by clinicians), taxation policy, restrictions on smoking in public places including workplaces, restaurants and hospitals, banning all tobacco promotion (including the introduction of plain packaging), support for quit attempts and monitoring and evaluation. There is an important role for the lung health community in engaging with, and supporting, this global campaign. In some countries, there has been substantial progress, with associated health benefits, ${ }^{6}$ but in much of the world there is a great deal still to do to achieve these benefits. ${ }^{7}$ Furthermore, the tobacco industry has fought tenaciously to defend its commercial interests, both overtly ${ }^{8}$ and covertly. ${ }^{9}$ These efforts must be strenuously resisted.

There is an important role for further epidemiological research on COPD, but probably there is little to be gained by further interrogating the role of smoking in causing this disease. Instead, we need to focus on the importance of other, potentially avoidable, causes of COPD, including occupational exposure to dust and fumes, ${ }^{10}$ indoor and outdoor air pollution, ${ }^{11}$ early-life nutrition ${ }^{12}$ and respiratory infections, including tuberculosis. ${ }^{13}$ A better understanding of exposure-response functions for these exposures should lead to cluster-randomised controlled trials of community-level interventions, designed to establish the role of such interventions in preventing the development of chronic lung disease. Together with ongoing concerted action against the scourge of tobacco, this pathway for research promises to lead to a world that will breathe more easily.

\section{Competing interests None declared.}

Provenance and peer review Commissioned; internally peer reviewed.

(C) Article author(s) (or their employer(s) unless otherwise stated in the text of the article) 2018. All rights reserved. No commercial use is permitted unless otherwise expressly granted.

\section{Check for updates}

To cite Marks GB. Thorax 2018;73:405-406.

Accepted 29 January 2018

Published Online First 14 February 2018

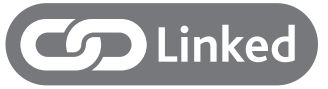

- http://dx.doi.org/10.1136/thoraxjnl-2017-210722

Thorax 2018;73:405-406.

doi:10.1136/thoraxjnl-2017-211356

\section{REFERENCES}

1 Bhatt SP, Kim Yl, Harrington KF, et al. Smoking duration alone provides stronger risk estimates of chronic obstructive pulmonary disease than pack-years. Thorax 2018;73:414-21.

2 Scherer G, Lee PN. Smoking behaviour and compensation: a review of the literature with metaanalysis. Regul Toxicol Pharmacol 2014;70:615-28.

3 Doll R, Peto R. Mortality in relation to smoking: 20 years' observations on male British doctors. Br Med J 1976;2:1525-36.

4 World Health Organization. Tobacco free initiative. 2018. 4 Jan 2018. http://www.who.int/tobacco/public ations/surveillance/reportontrendstobaccosmoking/en/ index1.html

5 Spires M, Rutkow L, Feldhaus I, et al. The World Health Organization's MPOWER framework and international human rights treaties: an opportunity to promote global tobacco control. Public Health 2014;128:665-7.

6 Adair T, Hoy D, Dettrick Z, et al. 100 years of mortality due to chronic obstructive pulmonary disease in Australia: the role of tobacco consumption. Int J Tuberc Lung Dis 2012;16:1699-705.

7 Singh RJ, Lal P. Tobacco control in India: where are we? Int J Tuberc Lung Dis 2016;20:288.

8 Mitchell AD, Studdert DM. Plain packaging of tobacco products in Australia: a novel regulation faces legal challenge. JAMA 2012;307:261-2. 
9 Kalra A, Bansal P, Wilson D, et al. Documents reveal Philip Morris' campaign to subvert the world's anti-smoking treaty. London, UK: Reuters,

2017.

10 Blanc PD, Iribarren C, Trupin L, et al. Occupational exposures and the risk of COPD: dusty trades revisited. Thorax 2009;64:6-12.
11 Adam M, Schikowski T, Carsin AE, et al. Adult lung function and long-term air pollution exposure. ESCAPE: a multicentre cohort study and meta-analysis. Eur Respir J 2015;45:38-50.

12 Stein CE, Kumaran K, Fall CH, et al. Relation of fetal growth to adult lung function in south India. Thorax 1997;52:895-9.
13 Byrne AL, Marais BJ, Mitnick CD, et al. Tuberculosis and chronic respiratory disease: a systematic review. Int J Infect Dis 2015;32:138-46. 